\title{
The Green Studio Handbook: Environmental Strategies for Schematic Design
}

\author{
Alison G. Kwok, Ph.D. ${ }^{1}$ and Walter T. Grondzik, P.E. ${ }^{2}$ \\ ${ }^{1}$ University of Oregon, Eugene, Oregon, USA \\ ${ }^{2}$ Architectural Engineer, Tallahassee, Florida, USA
}

\begin{abstract}
In design studio projects we often see schemes with inspired, yet unvalidated, gestural sketches related to wishful green strategies. Yellow and blue magic arrows represent hypotheses about the behavior of daylight and/or air flow in and about buildings. This paper provides an overview of The Green Studio Handbook, recently published as a resource for designers seeking clear guidelines for integrating green design strategies into the conceptual and schematic phases of design. The book contains a discussion of the integration of green strategies and how building form, orientation, and spatial layout are critical to the proper performance of certain green strategies; 40 green design strategies in six broad topic areas, each providing a catalog of information for common strategies that must be implemented at the schematic design phase; and nine case studies that show how various green strategies work together in a finished building. This paper provides excerpts of several design strategies and one case study and suggests a variety of ways that the book may be used.
\end{abstract}

Keywords: green design, case studies, education, schematic design

\section{INTRODUCTION}

In design studio, students often draw upon precedents to inspire their design work. Gesture sketches are refined and further developed. Green design strategies are commonly relegated to magic arrows (to show air flow) or yellow lines (to show the path of the sun or flux of light). Often, design hypotheses are left untested or unquestioned simply because there is no readily available method or means to appropriately size windows for cross ventilation or determine how much light will enter a room under particular sky conditions. This paper gives an overview of a number of green design strategies and case studies from a recently published work-The Green Studio Handbook (Architectural Press: Oxford, 2007)—which is offered as a resource to assist students (and practitioners) in integrating green strategies into the beginning stages of design.

The Green Studio Handbook presents guidelines for the application of selected environmental strategies during the schematic design of green buildings. The Handbook provides a discussion of green design at the schematic design phase and an essay on integrated design. The majority of the book is devoted to 40 design strategies, each providing: brief descriptions of principles and concepts, step-by-step approaches for integrating the strategy into the early stages of design, annotated tables and charts to assist with preliminary design sizing, key issues to be aware of when implementing the strategy, and references to further resources. This information is reinforced with conceptual sketches and photos illustrating each strategy. A chapter with case studies of several green building projects provides context for the strategies presented.

The rationale for this book arose from an observed need for a resource that could provide a concise catalog of information for a range of green strategies to help the designer not only understand how each strategy functions, but also offer data, information, and a sequence of design steps to give a preliminary estimate of sizing, appropriateness, and links to related strategies. The designer may practice "smart aesthetics" by linearizing part of the design process to achieve valid, initial design moves. The fundamental premise of this book is that if appropriate strategies are not included during the schematic design phase of a project, they may never be included since many such strategies are demandingly form-giving. Poor decisions related to building orientation, massing, and layout are nearly impossible to rectify in later design phases in an attempt to back-integrate high performance daylighting, passive heating, or passive cooling systems. 
This paper includes four parts:

- a discussion of the schematic design process, where design decisions about certain green strategies become critical to building form, orientation, and spatial layout;

- a review of several strategies describing the principle/concept, design procedure, and examples;

- a description of one of the case studies and its integrated strategies, including information regarding the designers' intentions with regard to green design, related design criteria, design validation methods used (modeling, simulation, hand calculations), and post occupancy validation methods if available;

- a discussion of how this book may be used in design studio and potentially in other areas of the curriculum.

\section{SCHEMATIC DESIGN PROCESS}

As a multifaceted pursuit, the design process includes cultural, technical, formal, and programmatic emphases that ultimately result in a proposed architectural expression. The green design process, by necessity, requires the designer (at least in the early schematic stages) to assume a greater than normal degree of expertise in several technical areas in order to pursue an integrated design. This necessity also represents an opportunity for innovation.

\subsection{Defining the Problem}

1.1.1 Schema: The early design process incorporates the moments when the project is conceptualized, the intentions are elaborated, and an organizational logic is settled upon-whether that logic is strict or informal, internalized or driven by externalities, or simply a geometric gesture. The first sketches or outlines, a plan of action, a systematic or organized framework can provide the opportunity to define goals and to set criteria that will benchmark success. This is the time to set a direction for form and to gather ideas and concepts. It is not the time, however, to close the mind and crystallize all relationships. The initial steps toward achieving an integrated design, such as forming a team with a shared set of green goals and a desire for innovation (and learning), is the territory wherein green strategies are initially discussed, adopted, and integrated. Opportunities for many of green strategies will be lost forever if not incorporated during schematic design.

1.1.2 Intentions: At the beginning a project, it is important to define owner and design team expectations for building performance. It should be decided whether the building will perform to minimum standards (as embodied in building codes) or will strive to surpass them-which must be the case for a green building. What kinds of performance will be emphasized: energy efficiency, quality of light, or air quality? What degree of green design is to be considered? The intentions must be clear because they point to the refinements of process, the type of team, and the potential strategies and technologies that will be most appropriate for a given project. Sometimes, a charismatic and knowledgeable team member can convert others to a deep green commitment.

1.1.3 Criteria: Project criteria are the standards by which judgments and decisions are tested. They are often established by a legal authority, local/regional custom, or general consent; but for innovative projects the truly critical criteria are often internally established. What is really meant by green? Who decides; and on what basis? Criteria can be derived from quantitative standards (such as energy efficiency) or from qualitative values (such as a desired lighting effect). Criteria should be realistic so they can be met; they should also be stringent enough to provide a challenge and meet design intent.

1.1.4 Validation: The design team must be conscious of the types of issues to be framed and the most appropriate design methods and strategies to address the focus issues. The way a designer frames issues speaks to the outcomes. More importantly, a knowledge-based profession reflects upon previous efforts and specifically learns from successes and failures. Collapses occurred during the construction of Chartres. Calculations and formulations about how materials work under the forces of gravity were rethought and the building of the famous cathedral continued. Knowledge-based design is also needed when dealing with environmental forces, although they are often more subtle, complex, and variable than gravity. A different type of feedback loop is required, one not founded upon collapse, but one that is part of an integrated processinvolving learning from others and learning from analysis. The analysis of an existing project (as a precedent or case study) informs the development of hypotheses of how things should work on future projects.

1.1.5 Prioritizing: It is important to give order to intentions and goals. Prioritizing goals helps the designer and client to understand what is most important, what can be discarded, and how flexible are proposed solutions. As with any design process, one works through sets of ideas to get to a clarification of goals. This is particularly important with green design because one strategy can negate or conflict with another. 


\subsection{Formgivers}

1.2.1 Daylighting: Light has clearly been understood as a formgiver throughout the history of architecture. The Pantheon dramatically captures light from an enormous oculus; Alvar Aalto's buildings use light scoops to utilize the low solar resource of the northern latitudes. Traditional passive solar design uses solar-oriented glazing in combination with thermal mass to provide heating. Windows, however, must be carefully sized and arranged to provide a balance between the correct amount of thermal resistance, light admittance, and solar collection. To arrive at a daylighting strategy, appropriate lighting level criteria should be established based upon the functions and needs of the various spaces, then potential solutions proposed, tested, and evaluated using daylighting models or other available tools. Such studies should provide for distinct lighting effects—and result in a distinct building form.

1.2.2 Passive and Active Strategies: Passive design means that nature (and the architect) does the work. Passive strategies adjust to environmental conditions primarily through the architecture and should be considered before active. This means that the architect must be strategic. It means using the resources on site rather than importing energy from a remote source. The careful placement of walls, windows, and overhangs can help to "green" a project; otherwise mechanical equipment (and engineering consultants) will be forced to do the job.

\section{GREEN DESIGN STRATEGIES}

The book contains 40 strategies (see Table 1), each with a brief description of underlying principles and concepts, a discussion of architectural design and implementation issues, a step-by-step design procedure to assist with preliminary design sizing, key issues to be aware of when considering a given strategy, conceptual sketches and photographic examples, and pointers to sources for further information. There are both active and passive strategies, but many more passive strategies are included since they require early implementation during the design process and are typically more form-shaping. Many green strategies (such as material finishes) are not included as they have virtually no impact on schematic design decisions. The book is not a catalog of green design strategies-it is a catalog of green strategies for schematic design.

Table 1: Green Strategies in The Green Studio Handbook

\begin{tabular}{lc}
\hline TOPIC and STRATEGIES & TOPIC and STRATEGIES \\
\hline ENVELOPE & COOLING \\
Insulation Materials & Cross Ventilation \\
Strawbale Construction & Stack Ventilation \\
Structural Insulated Panels & Evaporative Cool Towers \\
Double Envelopes & Night Ventilation of Mass \\
Green Roofs & Earth Cooling Tubes \\
& Earth Sheltering \\
LIGHTING & Absorption Chillers \\
Daylight Factor & \\
Daylight Zoning & HEATING \\
Toplighting & Direct Gain \\
Sidelighting & Indirect Gain \\
Light Shelves & Isolated Gain \\
Internal Reflectances & Active Solar Thermal Systems \\
Shading Devices & Ground Source Heat Pumps \\
Electric Lighting & \\
& ENERGY PRODUCTION \\
WATER AND WASTE & Plug Loads \\
Composting Toilets & Air-to-Air Heat Exchangers \\
Water Reuse/Recycling & Energy Recovery Systems \\
Living Machines & Photovoltaics \\
Water Catchment Systems & Wind Turbines \\
Pervious Surfaces & Microhydro Turbines \\
Bioswales & Hydrogen Fuel Cells \\
Retention Ponds & Combined Heat and Power \\
& \\
\hline
\end{tabular}




\subsection{Sample Strategy: Green Roofs}

Green roofs can be used for rainwater detention or retention, to increase the thermal resistance and capacitance of a roof assembly, to reduce the urban heat island effect, and/or to provide habitat for animals or an amenity for people on what would otherwise be a hard-surfaced area. Green roofs are of two basic types: extensive and intensive.

Extensive green roofs have a relatively shallow soil base, making them lighter, less expensive, and generally easier to maintain than intensive green roofs. Extensive roofs usually have limited plant diversity, typically consisting of sedum (succulents), grasses, mosses, and herbs. They are often not accessible to building users, but may provide for "natural" views from adjacent rooms or neighboring buildings. Extensive green roofs can work at slopes of up to 35 degrees, although slopes above 20 degrees require installation of a baffle system to prevent soil slump. These roofs can be used in both urban and rural settings, are applicable to a wide variety of building types, and can be used in both new and existing construction.

2.2.1 Key Architectural Issues: Successful green roofs require a building massing that permits appropriate solar exposure for the intended types of vegetation. Shading from adjacent buildings or trees can have a big impact on the success of rooftop plantings. Building massing can also be used to create rooftop surfaces that are relatively protected from wind. Building form will also determine how building occupants can interact with a green roof. A green roof is a user amenity only if it is at least visible to occupants. If it is also accessible to building occupants, greater integration of the green roof with appropriate interior spaces is desirable. Structural system design, careful detailing of drainage systems, irrigation systems, and penetrations of the roof membrane are key concerns.
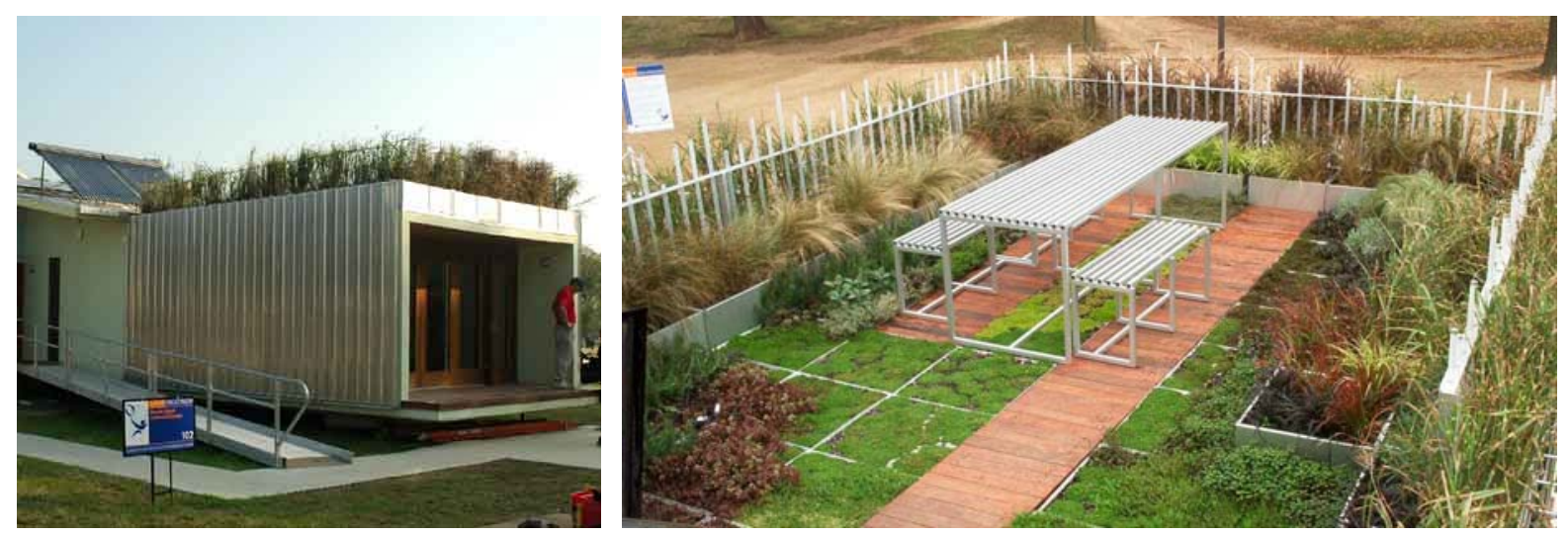

Figure 1: 2005 Rhode Island School of Design Solar Decathlon House with a green roof for outdoor dining.

\subsection{Sample Strategy: Cross Ventilation}

Cross ventilation establishes a flow of cooler outdoor air through a space; this flow carries heat out of a building. Cross ventilation is a viable and energy-efficient alternative to mechanical (active) cooling under appropriate climate conditions. The design may focus upon direct cooling of occupants as a result of increased air speed and lowered interior air temperature or upon the cooling of building surfaces (as with nighttime flushing) to provide indirect comfort cooling. Air speed is critical to direct comfort cooling; air flow rate is critical to structural cooling. The effectiveness of cross ventilation is a function of the size of the inlets, outlets, wind speed, and outdoor air temperature.

Cross ventilation cooling capacity is fundamentally dependent upon the temperature difference between the indoor air and outdoor air. Cross-ventilation cooling is only viable when the outdoor air is at least $3^{\circ} \mathrm{F}\left[1.7^{\circ} \mathrm{C}\right]$ cooler than the indoor air. Lesser temperature differences provide only marginal cooling effect (circulating air at room temperature, for example, cannot remove heat or reduce room temperature). Outdoor air flow rate is another key capacity determinant. The greater the air flow, the greater the cooling capacity.

Buildings are typically best naturally-ventilated when they are very open to breezes yet shaded from direct solar radiation. Building materials in a cross ventilated building may be light in weight, unless night ventilation of mass is intended-in which case thermally massive materials are necessary. 
2.3.1 Key Architectural Issues: Successful cross ventilation requires a building form that maximizes exposure to the prevailing wind direction, provides for adequate inlet area, minimizes internal obstructions (between inlet and outlet), and provides for adequate outlet area. An ideal building footprint is an elongated rectangle with no internal divisions. Siting should avoid external obstructions to wind flow (such as trees, bushes, or other buildings). On the other hand, proper placement of vegetation, berms, or wing walls can channel and enhance airflow to windward (inlet) openings.

2.3.2 Implementation Considerations: Cross ventilation for occupant comfort may direct air flow through any part of a space if the outdoor air temperature is low enough to provide for heat removal. At high outdoor air temperatures, cross ventilation may still be a viable comfort strategy if air flow is directed across the occupants (so they experience higher air speeds). Cross ventilation for nighttime structural cooling (when adequate wind speed exists) should be directed to maximize contact with thermally massive surfaces. A design caution: high outdoor relative humidity may compromise occupant comfort even when adequate sensible cooling capacity is available.

2.3.3 Design Procedure: Cross ventilation should normally be analyzed on a space by space basis. An exit opening equal in size to the inlet opening is necessary. This procedure considers only sensible loads and calculates the size of the inlet (assuming an equal sized outlet).

1. Arrange spaces to account for the fact that building occupants will find spaces near inlets (outdoor air) to be cooler than spaces near outlets (warmed air). Substantial heat sources should be placed near outlets, not near inlets.

2. Estimate design sensible cooling load (heat gain) for the space(s)_including all envelope and internal loads (but excluding ventilation/infiltration loads). [units are Btu/h or W]

3. State the design cooling load on a unit floor area basis. Btu/h $\mathrm{ft}^{2}$ or $\mathrm{W} / \mathrm{m}^{2}$

4. Establish the ventilation inlet area (this is free area, adjusted for the actual area of window that can be opened and the estimated impact of insect screens, mullions, shading devices) and the floor area of the space that will be cooled. The inlet area may be based upon other design decisions (such as view) or be a trial and error start to cooling system analysis. $\mathrm{ft}^{2}$ or $\mathrm{m}^{2}$

5. Determine the inlet area as a percentage of the floor area: (inlet area / floor area) $\times 100$

6. Using Figure 2 (see below), find the intersection of the inlet area percentage (Step 5) and the design wind speed (from local climate data). This intersection gives the estimated cross ventilation cooling capacity-assuming a $3^{\circ} \mathrm{F}\left[1.7^{\circ} \mathrm{C}\right]$ indoor-outdoor air temperature difference. Design wind speed should represent a wind speed that is likely to be available during the time of design cooling load.

7. Compare estimated cooling capacity (Step 6) with the required cooling capacity (Step 3).

8. Increase the proposed inlet area as required to achieve the necessary capacity; decrease the proposed inlet area as required to reduce excess cooling capacity.

This design procedure addresses "worst case" design conditions when outdoor air temperatures are usually high. Extrapolation beyond the values in Figure 2 for greater $\Delta$ ts is not recommended as a means of sizing openings. On the other hand, greater temperature differences will exist during the cooling season permitting a reduction in inlet and outlet size under such conditions. Extrapolation for higher wind speeds is not recommended due to discomfort from too-high indoor air speeds. Also, wind speeds at airport locations can be very different than at the city center or in suburban areas, depending upon the terrain. During schematic design, adjustments can be made to account for these variations by comparing "local" and airport wind speed data. As a rough estimate, urban wind speeds are often only a third of airport wind speeds; suburban wind speeds two-thirds of airport speeds. 


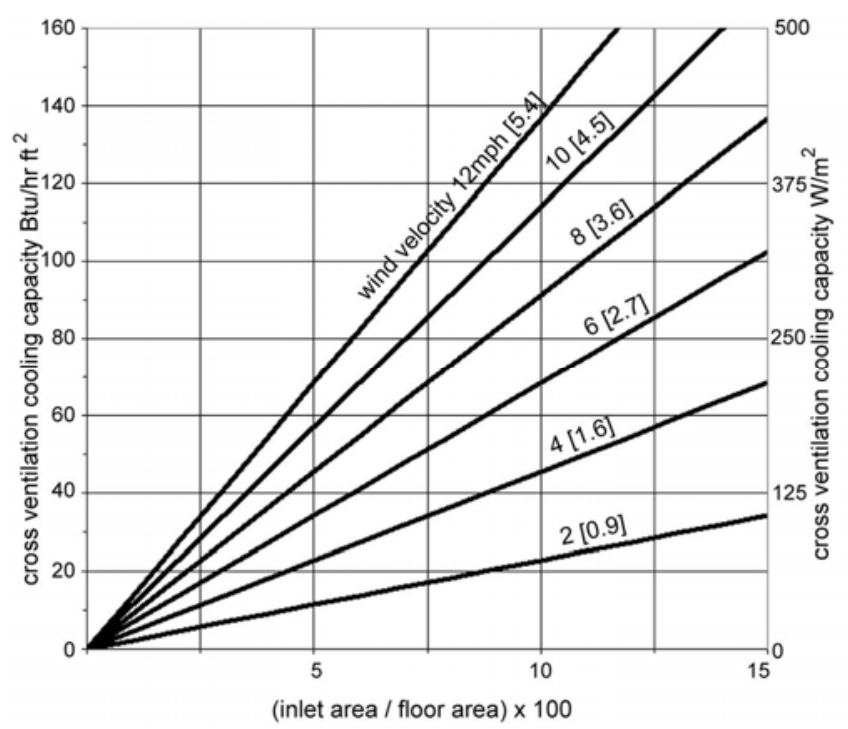

Figure 2: Cross ventilation cooling capacity. Heat removed per unit floor area (based upon a $3^{\circ} \mathrm{F}\left[1.7^{\circ} \mathrm{C}\right]$ temperature difference) as a function of size of inlet openings and wind speed.

\section{CASE STUDIES}

The nine case studies presented in the book (see Table 2) include a range of buildings selected to provide a diversity of geographic locations, climates, building types, and strategies. The design teams for these projects have made strong statements about green design intentions and have provided fertile ground for designers to learn from their projects. Each case study is organized as follows:

- A general description of the project

- A sidebar "scorecard" with building, climate, client, and design team information

- A statement of design intent and related design criteria

- Design validation methods employed (modeling, simulation, hand calculations, etc.)

- A description of the green strategies used

- Post occupancy validation results (if available).

Table 2: Case Study Projects in The Green Studio Handbook

\begin{tabular}{lll}
\hline PROJECT & LOCATION & ARCHITECT \\
\hline Arup Campus Solihull & Solihull, UK & Arup Associates \\
Beddington Zero Energy Development & Surrey, UK & Bill Dunster Architects \\
Cornell Solar Decathlon House & lthaca, NY, USA & Cornell University \\
Druk White Lotus School & Ladakh, India & Arup Associates \& ARUP \\
Habitat Research and Development Centre & Windhoek, Namibia & Nina Maritz \\
The Helena Apartment Tower & New York, NY, USA & FX FOWLE \\
Lillis Business Complex & Eugene, OR, USA & SRG Partnership \\
National Association of Realtors Headquarters & Washington, DC, USA & The Gund Partnership \\
One Peking Road & Hong Kong, China & Rocco Design Ltd. \\
\hline
\end{tabular}

\subsection{Sample Case Study: Lillis Business Complex}

The University of Oregon's Lundquist College of Business needed to replace an aging building that connected three existing smaller buildings. The building's site, along an axis between the historic entrance to the college and the main library, gives it a high profile. The university had in place a campus-wide sustainable development plan and Lundquist College had a commitment to certain sustainability goals-as a result both parties had a mutual desire to aim for the greenest building possible. 
The University engaged a Construction Manager/General Contractor who was brought into the project early in the design process. This enabled the design team to work closely with the GM/GC as the design developed, ensuring that the design was feasible and within the established financial parameters. Lillis was a complex project - to be built in the middle of an active campus, while minimally disrupting classes.
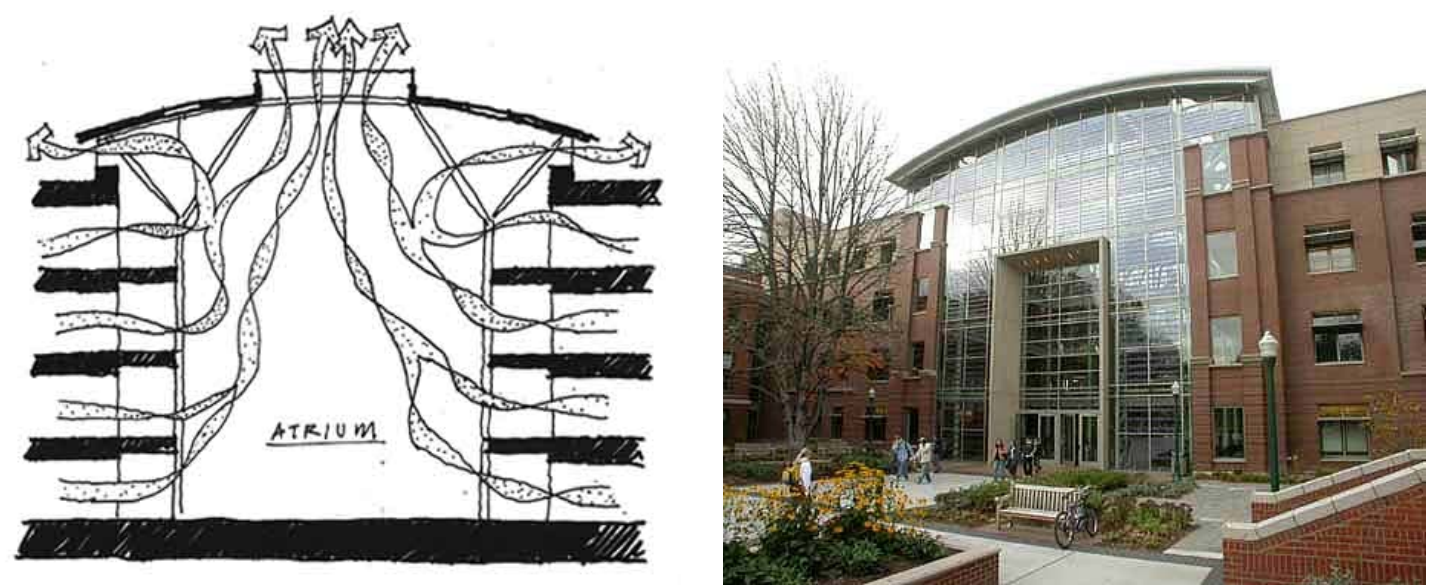

Figure 3: Early conceptual sketch (left) of air flow patterns through the Lillis Business Complex atrium (courtesy of SRG Partnership); entry plaza (right) with a façade of laminated glass with integrated photovoltaics.

3.1.1 Design Intent and Validation: The client and designers began with a goal to achieve a building that would be at least $40 \%$ more efficient than required by the Oregon Energy Code. The designers were also asked to follow a process that could result in a solution with the performance of a LEED (the US Green Building Council's Leadership in Energy and Environmental Design program) accredited building. The decision to pay for the formal LEED process, however, was not made until after the designers had finished working drawings. To make these goals a reality, the design team developed complementing strategies involving daylighting, solar control, natural ventilation, electricity generation using photovoltaic arrays, expanding the thermal comfort zone (by occupant cooling with ceiling fans), night ventilation of thermal mass, and wiring half of all the plug load receptacles and lighting circuits in faculty offices on occupancy sensors. A team of consultants, including energy engineers and daylighting experts, modeled various designs to determine how well design concepts were meeting project goals. The CM/GC agreed to recycle $95 \%$ of the demolition waste from the existing buildings (related to LEED Materials \& Resources credits).

\subsubsection{Strategies}

3.1.2.1 Orientation and form. The designers conceived of the building as a long and thin form running along an east-west axis. The north- and south-facing windows are easy to control relative to daylighting and solar gain and they take advantage of the prevailing seasonal wind directions on site (from the north and south).

3.1.2.2 Natural ventilation. In addition to the long and thin form, the auditorium and lecture hall push out beyond the primary edge of the building, providing these rooms with more building skin, and more opportunity for clerestory windows and skylights to act as inlets/outlets for natural ventilation. A four-story atrium organizes the building spatially and provides a means for stack ventilation.

3.1.2.3 Solar control and daylighting. When the building is in cooling mode, computers automatically close shades or skylight louvers in unoccupied rooms to minimize solar gains. When people enter a room, the computer control opens the shades/louvers as far as necessary to reach a targeted illuminance for the space. Using daylight not only makes people happy and more productive, it is a "free" source of light and produces less heat for a given illuminance than electric lighting. Lightshelves are used on the south-facing windows. External overhangs shade the windows, especially from the high summer sun, and effectively reduce cooling loads. 

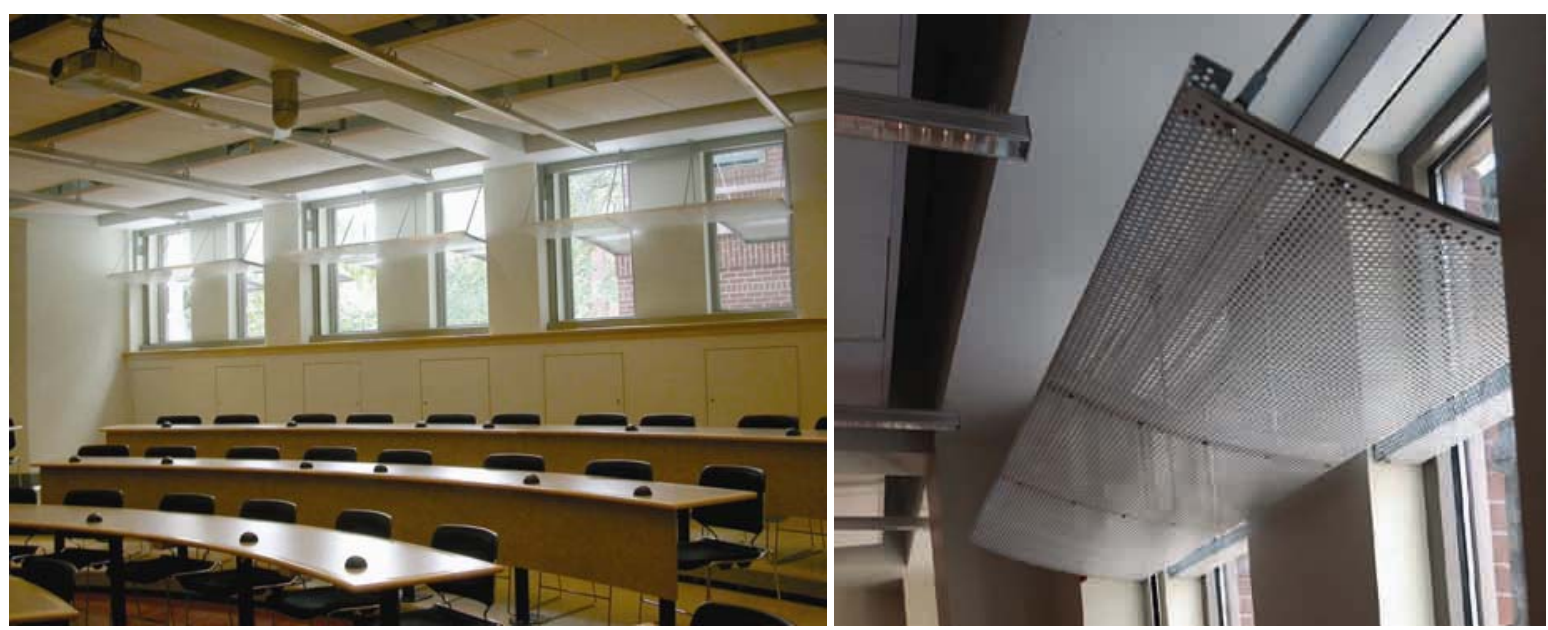

Figure 4: Light shelves and ceiling fans in a south-facing Lillis classroom (left photo courtesy of Emily J. Wright; right photo courtesy of SRG Partnership).

3.1.2.4 Integrated cooling systems. Outside air is used to cool the building and the occupants as much as possible before relying on mechanically-cooled air. A mixed-mode cooling system, as well as night ventilation of mass, provides for a high-efficiency cooling approach.

3.1.2.5 Hybrid ventilation. Classrooms have raised concrete floors, arranged into risers for seating. Air is drawn in from the outdoors, passes under the floor slab and enters the room through outlets in the risers. If the outdoor air is too warm to effectively cool a space, it can be mixed in a plenum with mechanically-conditioned air. The air from the classroom is exhausted into the atrium, rising to the top and exiting through gravity ventilators. Eugene's cool nighttime temperatures make night ventilation of mass a viable strategy. The raised concrete floor slab absorbs heat during the day as the outside temperature rises and the sun and occupants add heat to the space.

3.1.2.6 Photovoltaics. The south-facing glass curtain wall with integrated polycrystalline photovoltaic cells comprises a $5.9 \mathrm{~kW}$ array. There are translucent PV panels in the skylights, which are equivalent to a $2.7 \mathrm{~kW}$ array. Roof panels on the mechanical room produce $6.2 \mathrm{~kW}$, and other roof sub-arrays provide $29.9 \mathrm{~kW}-$ for a grand projected total of $45 \mathrm{~kW}$ of PV power. The local utility played a key role in providing financial incentives for this signature renewable energy feature.

\section{CONCLUSIONS}

The Green Studio Handbook is purposely not a comprehensive manual on building science; nor is it a "how-toget-a-green-rating" handbook. Although the book is partly a compilation of strategies, it is intended that these strategies be applied in the context of a well-organized design process-where the architect is an active participant in the shaping of a green building and in coordinating the integration of green design strategies. Passive or active strategies can be used to achieve green building status. While these approaches may provide similar quantitative building performance, the way they reach that point is very different in both process and form.

It is our belief that architects are the ones who must guide the inclusion and integration of green strategies. The ability to do so is becoming increasingly critical in the face of growing client and societal interest in green buildings, burgeoning discussion of "sustainability," and a recent call to develop carbon-neutral (or carbonresponsible) buildings. We hope and expect that this book is adopted by students as a self-selected required reading for their design courses. Practice is essential to confidence; the how-to experience gained through studio implementation will become more and more a part of the graduating designer's inner understanding. Then it will flow into practice. Students are likely to be the real agents of change.

\section{ACKNOWLEDGEMENTS}

The authors gratefully acknowledge the contributions of Laura Briggs and Jonathan Knowles to The Green Studio Handbook's chapter on design process, portions of which are presented (in edited form) in Section 1 of this paper. The nomograph shown in Figure 2 was developed by Kathy Bevers from equations in Mechanical and Electrical Equipment for Buildings, $10^{\text {th }}$ edition. 